\title{
Laparoscopic Reversal of Hartmann's Procedure (eLapRHP)
}

\author{
Anil Bagu' ${ }^{*}$, M Shrotri \\ Department of Colorectal Surgery, University Hospital of Aintree, UK
}

"Corresponding author: Anil Bagul, Department of Colorectal Surgery, University Hospital of Aintree, Aintree, UK. Tel: +441515255980; Email: anil.bagul@nhs.net

Citation: Bagul A, Shrotri M (2017) Laparoscopic Reversal of Hartmann's Procedure (eLapRHP). J Surg: JSUR-138. DOI: 10.29011/JSUR-138.000038

Received Date: 11 May, 2017; Accepted Date: 10 August, 2017; Published Date: 18 August, 2017

\begin{abstract}
Introduction: Restoration of continuity of colon after a Hartmann's procedure is associated with substantial morbidity and mortality. Traditionally the procedure is carried out as an open procedure. Implementation of laparoscopic technique has been employed in our series of cases. We describe our experience in a series of patients who underwent a laparoscopic reversal of Hartmann's procedure (eLapRHP).

Aim: To analyse our experience at eLapRHP.

Methods and Results: Ten patients underwent laparoscopic reversal of Hartmann's procedure (LapRHP) at University hospital of Aintree by one consultant. All cases had initial surgery for peritonitis due to diverticular perforation. Laparoscopic approach was successful in all cases. The median time to closure of colostomy was 5.5(2-14) months. The mean inpatient stay was 6(4-15) days. Median operation time was 3.25(2.5-5) hours. Minor complications such as ileus and wound infection were seen in 2(22.2\%). There were no anastomtic leaks and no mortality. Follow up period was 6(2-12) months. No long-term complications seen.
\end{abstract}

Conclusion: eLapRHP is a safe alternative to the traditional open reversal procedure and should be a recommended approach.

\section{Background}

Hartmann's procedure is a standard operation carried out in treatment of complicated left side colon disease as an emergency in patients with sepsis and perforation. After recovery from initial surgery, colostomy reversal and restoration of the bowel continuity is indicated in selected number of patients. The procedure can be a difficult major procedure carrying serious risk of a significant morbidity [1]. The reanastomotic rates are reported at 4 to $16 \%$ and mortality around $10 \%$ [2]. Previously reported small series comparing Laparoscopic to open procedure suggests shortened lengths of inpatient stay, lower morbidity and no mortality [3]. Our series reports our experience of eLapRHP.

\section{Case Series}

Ten patients underwent at eLapRHP University hospital Aintree, all patients were operated on by a single surgeon. The primary Hartmann's procedure had been performed on all patients by a midline Laparotomy incision. The initial operation was per- formed to manage acute diverticular perforations in all cases.

The first step was to make a circumferential incision around and mobilise the stoma with blunt and sharp dissection. Once this was achieved a CEEA stapler gun head was introduced in the prepared proximal end of the stoma and fixed in place with a purse string. The anvil of the stapling device was inserted into the proximal colon and returned to the peritoneum and sheath was closed with PDS. Access to the peritoneum was gained via a $11 \mathrm{~mm}$ port which was introduced at the stoma closure site, in most cases two $11 \mathrm{~mm}$ and two $5 \mathrm{~mm}$ ports were placed under direct vision.

The $11 \mathrm{~mm}$ camera port is introduced above or below the main opening at the stoma site depending on case preference. Laparoscopic adhesionolysis was performed with cautery and sharp dissection. Mobilisation of the left colon and splenic flexure was carried out to facilitate a tension free anastomosis with the rectal stump [4,5]. A Transanal, end-to-end Anastomosis was made with a circular stapling device (CEEA stapler) illustrated in (Figures $1-3)$. 
Citation: Bagul A, Shrotri M (2017) Laparoscopic Reversal of Hartmann's Procedure (eLapRHP). J Surg: JSUR-138.
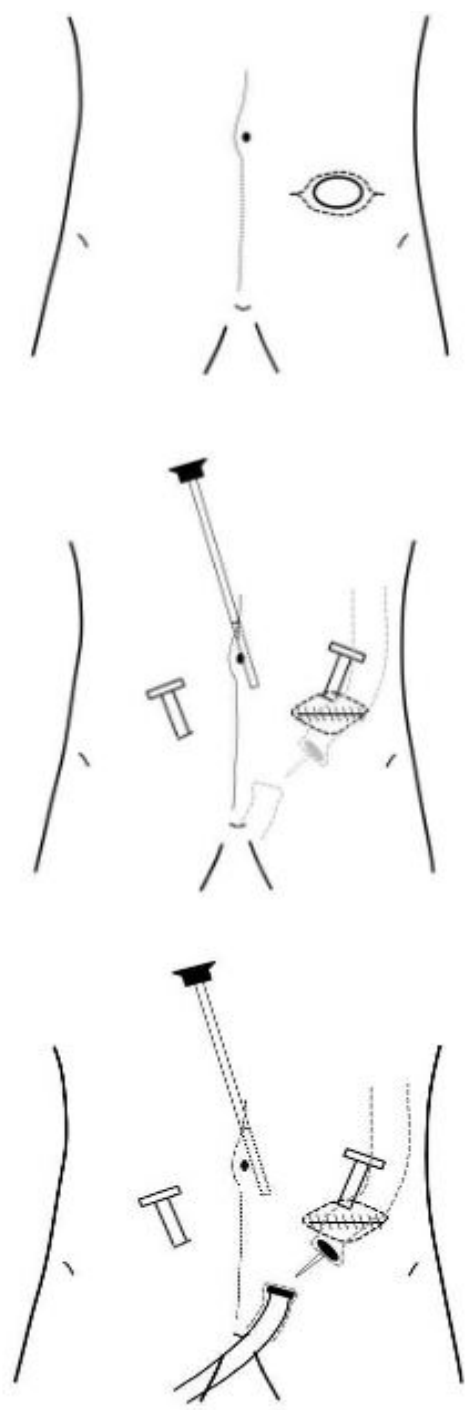

Figure 1-3: A Transanal, end-to-end Anastomosis was made with a circular stapling device.

The patients were discharged home in 48 to 72 hours with a follow up appointment in 6 weeks. (Table 1).

Perioperative data and demographics are summarised in

\begin{tabular}{|c|c|c|}
\hline $\mathrm{N}$ & 10 & \\
\hline Age & $58(32-66)$ & \\
\hline Sex M/F & $8 / 2$ & \\
\hline BMI & $27(21-36)$ & \\
\hline ASA & $2(2-3)$ & \\
\hline Hospital Stay & $6(4-15)$ & \\
\hline Complications & $3(30 \%)$ & \\
\hline Major & Small bowel leak & $1(10 \%)$ \\
\hline
\end{tabular}

\begin{tabular}{|l|c|c|}
\hline \multirow{2}{*}{ Minor } & Ileus & $2(22.2 \%)$ \\
& Wound infection & $3(30 \%)$ \\
\hline
\end{tabular}

Table 1: Perioperative data and Demographics.

Time interval from the original surgery to the reversal of colostomy was 6.5 months. The mean age of patients was 58(32-66) years. The procedure was completed laparoscopically in all cases. Mean hospitalisation stay was 6(4-15) days. The median operation time was 3.25 hours ( 2.5 - 5.0 hours). Post-operative complication was seen in $3(30 \%)$. No mortality was recorded.

\section{Discussion}

Reversal of Hartmann's procedure is associated with significant morbidity and mortality, especially in cases where index operation was because of a malignant disease where the operation is carried out for an obstruction/perforation. The procedure is technically more demanding because of higher incidence of denser adhesion post radiotherapy treatment. ELapRHP is not currently popular but recent reports highlight the advantages of minimally invasive surgery compared to the convential open procedure [6-7]. Bergamaschi, et al. reported decreased complications and reoperation rates at 6 months follow up compared to their open group [8]. The overall mortality rate was 0 to $7.1 \%$ and morbidity rate after eLapRHP was reported as 2.8 to $18 \%$. These were significantly better in the laparoscopic group [7,8]. Literature review suggests a conversion rate of 15 to $23.5 \%$ [9]. In our series adhesion resulting from sequel of previous inflammatory process due to perforated diverticulitis did not limit the success of laparoscopic completion but we agree it may be challenging. In our series, we performed careful and meticulous sharp and blunt dissection.

\section{Conclusion}

We conclude that eLapRHP is safe and feasible but can be a challenging and difficult procedure. Our study results show that morbidity and mortality is low when performed by an experienced laparoscopic surgeon.

\section{References}

1. Banerjee S, Leather AJ, Rennie JA, Samano N, Gonzalez JG, et al. (2005) Feasibility and morbidity of reversal of Hartmann's. Colorectal Dis 7: 454-459.

2. Griffa C, Basilico V, Bellotti R, Sacchi F, Senatore S, et al. (2004) CoIon recanalization after Hartmann's procedure. A challenge for the surgeon or a strategy to be changed? Minerva Chir 59: 489-493.

3. Vacher C, Zaghloul R, Borie F, Laporte S, Callafe R, et al. (2002) Laparoscopic re-establishment of digestive continuity following Hartmann's procedure. Retrospective study of the French society of Endoscopic surgery. Ann Chir 127: 189-192.

4. Lucarini L, Galleano R, Lombezzi R, Ippoliti M, Ajraldi G (2000) Laparoscopic-assisted Hartmann's reversal with the dexterity Pneumo sleeve. Dis Colon Rectum 43: 1164-1167. 
Citation: Bagul A, Shrotri M (2017) Laparoscopic Reversal of Hartmann's Procedure (eLapRHP). J Surg: JSUR-138.

5. Jacob BP, Gagner M, Hung TI, Fukuyama S, Waage A, et al. (2004) Dual endoscopic-assisted endoluminal colostomy reversal: A feasibility study. Surg Endosc 18: 433-439.

6. Mazeh H, Greenstein AJ, Swedish K, Nguyen SQ, Lipskar A, et al. (2009) Laparoscopic and open reversal of Hartmann's procedure: a comparative retrospective analysis. Surg Endosc 23: 496-502.

7. Van de Wall BJ, Draaisma WA, Schouten ES, Broeders IA, Consten EC (2010) Conventional and laparoscopic reversal of Hartmann's procedure: a review of literature. J Gastrointest surg 14: 743-752.
8. Haughn C, Ju B, Uchal M, Arnaud JP, Reed JF, et al. (2008) Complication rates after hartmann's reversal: open vs laparoscopic approach. Dis Colon Rectum 51: 1232-1236.

9. Faure JP, Doucet C, Essique D, Bader Y, Richer JP, et al. (2007) Comparison of conventional and laparoscopic Hartmann's procedure reversal. Surg Laparosc Endosc Percutan 17: 495-499. 